\title{
Abnormal Circulatory Stress Responses of Preterm Graduates
}

\author{
GARY COHEN, HUGO LAGERCRANTZ, AND MIRIAM KATZ-SALAMON
}

\author{
Department of Women and Child Health, Neonatal Unit, Karolinska Institute, S-171 76 Stockholm, Sweden
}

\begin{abstract}
Preterm birth and chronic lung disease may increase the risk of hypertension and cardiovascular disease in infancy and adolescence. Here we looked for evidence of early circulatory dysfunction associated with these perinatal complications. We compared infants born at term $(n=12)$ with those born preterm with an uncomplicated neonatal course $(n=12)$ or diagnosed with bronchopulmonary dysplasia (BPD) $(n=10)$. We measured blood pressure (BP) (Finometer), and heart rate (HR) responses to 4 min of breathing $4 \% \mathrm{CO}_{2}$ during quiet sleep. Hypercapnia accelerated HR and increased BP of term infants. Preterm infants either (i) had an exaggerated pressor but little or no $\mathrm{HR}$ response to $\mathrm{CO}_{2}$ (healthy or mild-moderate BPD) or (ii) had a diminished pressor response and accompanying decrease in HR (severe BPD). Short-term reflex cardiovascular control was consequently altered by premature birth, with potentially more serious aberrations associated with severe BPD. Most anomalies had not resolved by the time infants born preterm reached term age; some may be early signs of emerging long-term cardiovascular dysfunction. (Pediatr Res 61: 329-334, 2007)
\end{abstract}

$\mathrm{W}$ ith the impressive increase in survival of very preterm and low birth weight infants come new challenges. Evidence already indicates that this "new generation" of children and adolescents may have accelerated disease onset later in life (1). One factor contributing to their higher risk of cardiovascular disease may be abnormal vascular and circulatory development (2-4). Cardiovascular activity is normally carefully regulated, but if some or all of the central and peripheral regulatory mechanisms involved fail to develop normally, perfusion, growth, and function may be compromised. In exceptional circumstances during infancy, persistent serious dysfunction could result in a sudden catastrophic decrease in BP and HR or prevent autoresuscitative recovery, culminating in sudden infant death syndrome (SIDS) $(5,6)$. In other cases, dysfunction may be relatively benign, although there may still be side effects with adverse consequences of their own.

We know relatively little about how BP and HR control develops, and the potentially adverse effects of fetal and perinatal stress. A better understanding of these issues could

Received June 21, 2006; accepted October 11, 2006.

Correspondence: Miriam Katz-Salamon, Ph.D., Department of Women and Child health, Neonatal Unit, Karolinska Institute, Elevhemmet H1 02, S-171 76 Stockholm, Sweden; e-mail:Miriam.Katz-Salamon@karolinska.se

Supported financially by Flight Attendants Medical Research Institute (FAMRI), Torsten och Ragnar Söderbergs Stiftelser, The Laerdal Foundation for Acute Medicine, The Swedish Medical Research Council, Heart and Lung Foundation, Sällskapet Barnavård, Karolinska Institute Research Fund, and Stiftelsen Samariten.

DOI: $10.1203 /$ pdr.0b013e318030d0ef lead to new therapies or strategies to prevent neonatal complications and improve long-term outcome. In the study described here, we looked for evidence that development of neonatal circulatory control is altered by common perinatal complications (7). We studied three different groups of newborn infants: those born normally at term, those born preterm but otherwise healthy, and infants born very preterm suffering from chronic lung disease (BPD). Infants with BPD are at particularly high risk of long-term cardiovascular complications and SIDS (8-10). We compared BP and HR responses of these infants to a routine physiologic stress (breathing a low concentration of $\mathrm{CO}_{2}$ for several minutes) commonly used to unmask autonomic anomalies (11). Normally, acute exposure to $\mathrm{CO}_{2}$ increases $\mathrm{BP}$ and $\mathrm{HR}$ slightly. A heightened/attenuated increase, and/or a failure to recover promptly may indicate that reflexes involved in cardiovascular control have not developed normally. Our hypotheses were (i) short-term control of BP and HR is altered by preterm birth and lung disease; (ii) these functional changes resolve slowly, if at all, and are still evident when infants born preterm reach term age; and (iii) dysfunction is more persistent and serious when associated with BPD.

\section{METHODS}

We compared infants born at term $(38-42 \mathrm{wk})$ with healthy infants born preterm (27-34 wk of gestation) and those born preterm (23-33 wk) diagnosed with BPD (Table 1). All were appropriately grown. Term infants were studied 2-5 d after birth, and preterm infants at 36 and $40 \mathrm{wk}$ postmenstrual age. Healthy preterm infants had an uncomplicated neonatal course (no respiratory abnormalities, patent ductus arteriosus, intraventricular hemorrhage, or septicemia). BPD was staged clinically (12) as (a) mild, supplemental $\mathrm{O}_{2}$ for $\geq 28 \mathrm{~d}$ but breathing room air at $36 \mathrm{wk}$ (two infants); (b) moderate, $<30 \% \mathrm{O}_{2}$ at $36 \mathrm{wk}$ (three infants); and (c) severe, $>30 \% \mathrm{O}_{2}$ at $36 \mathrm{wk}$ (five infants). None of our subjects required positive airway pressure or ventilation at 36 wk. Two infants with severe BPD were diagnosed with germinal matrix/grade II intraventricular hemorrhage. All infants with BPD received inhalation steroids (Pulmicort 400-600 mg/d) and a bronchodilator (Salbutamol), and those with severe BPD also received diuretics.

Infants slept supine. BP was recorded from a wrist cuff (Finometer, FMS, The Netherlands; for accuracy, the "physiocal" function was always enabled) (13). To alleviate venous congestion in the hand, cuff inflations were limited to $10 \mathrm{~min}$ (several inflations were needed to complete the protocol). Chest and abdominal movements (Respitrace), transcutaneous $\mathrm{PO}_{2}\left(\mathrm{TcO}_{2}\right)$ and transcutaneous $\mathrm{PCO}_{2}\left(\mathrm{TcCO}_{2}\right)$ (Radiometer TCM3 electrode, Copenhagen), oxygen saturation $\left(\mathrm{SaO}_{2}\right.$; finger probe) and an electrocardiogram were recorded (Rembrandt, MedCare Automation, The Netherlands). $\mathrm{CO}_{2}$ (duplicate challenges) was administered during behavioral quiet sleep (14) via a 10-L head box. Tests comprised $2 \mathrm{~min}$ of baseline (room air), $4 \mathrm{~min}$ of $4 \% \mathrm{CO}_{2}$, then 4 min of recovery (air). Head box gas flow was $10 \mathrm{~L} / \mathrm{min}$, and supplemental $\mathrm{O}_{2}$ (if required) was delivered via nasal prongs at the prescribed concentration and flow.

Abbreviations: BPD, bronchopulmonary dysplasia; HVR, hypercapnic ventilatory response; $\mathbf{T c C O}$, transcutaneous $\mathrm{PCO}_{2}$ 
Table 1. Population data

\begin{tabular}{|c|c|c|c|c|c|c|c|c|}
\hline \multirow[b]{2}{*}{ Group } & \multirow{2}{*}{$\begin{array}{c}\text { Gestation } \\
\text { at birth (wk) }\end{array}$} & \multirow[b]{2}{*}{ Birth weight (g) } & \multicolumn{3}{|c|}{ Study at 36 wk PMA } & \multicolumn{3}{|c|}{ Study at term PMA } \\
\hline & & & Weight (g) & Age (d) & Age (wk) & Weight (g) & Age (d) & Age (wk) \\
\hline Full term $(n=12)$ & $40(38-42)$ & $3575(3065-4645)$ & & & & $3575(3065-4645)$ & $5(2-10)$ & $41(39-41)$ \\
\hline $\operatorname{Preterm}(n=12)$ & $32(27-34)$ & $1530(1144-2640)$ & $2410(1886-2960)$ & $28(13-64)$ & $36(34-37)$ & $3060(2546-3480)$ & $62(41-85)$ & $40(40-40)$ \\
\hline $\operatorname{BPD}(n=10)$ & $26(23-33)$ & $875(500-2342)$ & $2412(1400-2955)$ & $63(15-90)$ & $36(36-36)$ & $3150(2400-3660)$ & $93(46-117)$ & $40(39-40)$ \\
\hline
\end{tabular}

Details of the three infant study groups. The median and range (min-max) are shown. Note that full-term infants were only studied once. PMA, postmenstrual age $(=$ postconceptual age + postnatal age $)$.

Analysis. Recordings were checked and artifacts due to sighs or startles were excluded. Tests complicated by prolonged arousal (artifact exceeding $10 \%$ of the recording period) or transitions between sleep states were excluded. Cardiorespiratory and $\mathrm{TcCO}_{2}$ signals were analyzed using appropriate software (Beatscope V1.1, FMS, and Rembrandt Automation; Statgraphics V15, StatPoint Inc.), and an average response was calculated for each infant. Because our BPD study group was small $(n=10)$, we pooled data from babies with mild and moderate BPD $(n=5)$ and compared these with babies diagnosed as severe $(n=5)$.

HR, systolic, diastolic, and pulse (systolic - diastolic) pressures were calculated from beat-to-beat data collected during baseline, $\mathrm{CO}_{2}$ exposure, and recovery. We focused principally on relative changes from baseline (=30 s preceding $\mathrm{CO}_{2}$ ). Means of sequential 30-s epochs were plotted against elapsed time to generate time-dependent profiles. Respiratory rate (RR), breath amplitude (tidal volume, $\mathrm{V}_{\mathrm{T}}$ ), and the product (ventilation; $\mathrm{V}=$ $R R \times V_{T}$ ) were calculated from the frequency and amplitude, respectively, of chest and abdominal movements. $\mathrm{V}_{\mathrm{T}}$ was proportional to the sum of chest and abdominal amplitudes (15). Increases in the rate $(\Delta R R)$ and depth $\left(\Delta V_{T}\right)$ of breathing were expressed as relative changes from baseline and were plotted against the corresponding change in $\mathrm{TcCO}_{2}$. We took into account the time lag in response of the $\mathrm{TcCO}_{2}$ electrode (approx $15 \mathrm{~s}$ ). The strength of the hypercapnic ventilatory response (HVR) was the slope of the line relating instantaneous $\mathrm{V}$ and $\mathrm{TcCO}_{2}$.

Statistics. Cardiovascular data were normally distributed and analyzed via two-way analysis of variance (ANOVA) to test for significant main (time, group) and interaction effects, followed by pairwise comparisons of means using multiple range tests with the Bonferroni correction. Respiratory data were not normally distributed and hence were analyzed using nonparametric tests. We tested for differences between HVRs (Kruskal-Wallis test) and analyzed whether the HVR was due to changes in amplitude or rate of breathing (or both; Spearman's rank correlation test). We also tested for a positive or negative (or no) association between BP, HR, and ventilatory response by pairwise ranking of slopes (Spearman's rank correlation test). A $p$ value $\leq 0.05$ indicated significant differences/correlations at the $95 \%$ confidence level. Measurement error is presented as standard deviations (SDs) in the text, and (for clarity) standard error of the mean (SEM) in the figures.

The Karolinska University Hospital Ethics Committee approved all procedures, and written informed consent was obtained from parents of infants who participated.

\section{RESULTS}

Baseline data: Asleep, breathing air. We analyzed data from $94 \mathrm{CO}_{2}$ tests (35 for preterm, 39 for BPD, and 20 for full-term infants). Babies with severe BPD had a higher resting $\mathrm{TcCO}_{2}$ and respiratory rate at $36 \mathrm{wk}$ than did infants with mild-moderate or no disease; HRs and transcutaneous $\mathrm{O}_{2}$ levels were comparable for all infants born preterm; however, the $\mathrm{SaO}_{2}$ was slightly lower in severe BPD (Table 2A). At term, the respiratory rate and $\mathrm{TcCO}_{2}$ of infants with severe BPD had decreased slightly. Preterm infants in general had higher resting HR and respiratory rates than did infants of the same age born at term (Table 2B).

$B P$ and HR responses: healthy infants. Our purposes here was to determine whether cardiovascular responses to $\mathrm{CO}_{2}$ were altered after preterm birth. All groups received a comparable $\mathrm{CO}_{2}$ load $\left(\Delta \mathrm{TcCO}_{2}=\right.$ mean during 4 th $\min -$ baseline $=$ $1.0 \pm 0.6 \mathrm{kPa}, 1.3 \pm 0.4 \mathrm{kPa}$, and $1.1 \pm 0.5 \mathrm{kPa}$ for term versus preterm at 36 and $40 \mathrm{wk}$, respectively). The resulting increase in mean BP (the pressor response) was exaggerated at $36 \mathrm{wk}$, but had normalized by term (Fig. 1A,D). The pressor response always outlasted the stimulus, with BP remaining elevated long after $\mathrm{TcCO}_{2}$ returned to baseline (Fig. 1A,D). Pulse pressure returned to baseline more quickly than mean BP (Fig. 1B,E). The HR of term infants increased promptly during $\mathrm{CO}_{2}$ exposure and slowly returned to baseline during recovery, a response that was relatively subdued and delayed ("phase-shifted") for infants born preterm (Fig. 1C,F).

$B P$ and HR response of infants with BPD. Here we analyzed how lung disease influenced cardiovascular control. Baseline $\mathrm{TcCO}_{2}$ was elevated in severe BPD, but the increase in $\mathrm{CO}_{2}$ during hypercapnia was comparable across the $\mathrm{BPD}$ spectrum $\left(\Delta \mathrm{TCO}_{2}=1.1 \pm 0.5 \mathrm{kPa}\right.$ versus $1.0 \pm 0.5 \mathrm{kPa}$ for mild-moderate versus severe BPD, respectively; Fig. $2 A$ ). Infants with mild-moderate BPD had a comparable pressor response to that of healthy preterm infants, but in severe BPD, the pressor response was markedly diminished (Fig. 2B,C).

Table 2. Baseline data

\begin{tabular}{|c|c|c|c|c|c|}
\hline Group & $\operatorname{HR}\left(\min ^{-1}\right)$ & $\mathrm{RR}\left(\min ^{-1}\right)$ & $\mathrm{TcCO}_{2}(\mathrm{kPa})$ & $\mathrm{TcO}_{2}(\mathrm{kPa})$ & $\mathrm{SaO}_{2}(\%)$ \\
\hline \multicolumn{6}{|c|}{ A. Baseline data at $36 \mathrm{wk}$ PMA } \\
\hline Preterm $(n=12)$ & $144 \pm 7$ & $52 \pm 4$ & $5.8 \pm 0.1$ & $8.3 \pm 0.9$ & $98 \pm 1$ \\
\hline Mild BPD $(n=5)$ & $145 \pm 1$ & $51 \pm 7$ & $5.8 \pm 0.1$ & $8.0 \pm 0.9$ & $98 \pm 2$ \\
\hline \multicolumn{6}{|c|}{ B. Baseline data at term PMA } \\
\hline Full term $(n=12)$ & $121 \pm 6$ & $41 \pm 3$ & $5.3 \pm 0.2$ & $9.4 \pm 0.7$ & $96 \pm 1$ \\
\hline Preterm $(n=12)$ & $137 \pm 5 \dagger$ & $44 \pm 2$ & $5.6 \pm 0.2$ & $8.9 \pm 0.6$ & $98 \pm 1$ \\
\hline
\end{tabular}

Baseline values measured in air, during quiet sleep at PMA $36 \mathrm{wk}(\mathrm{A})$ and $40 \mathrm{wk}(\mathrm{B})$. Values are mean $\pm \mathrm{SD}$. There was significant $\mathrm{CO}_{2}$ retention in babies with severe BPD at $36 \mathrm{wk}(\mathrm{A})$; preterm infants had higher HRs compared with term babies at the same age (B).

* Significantly different from preterm and mild BPD.

$\dagger$ Significantly different from term.

$\ddagger$ Significantly different from preterm (ANOVA). 

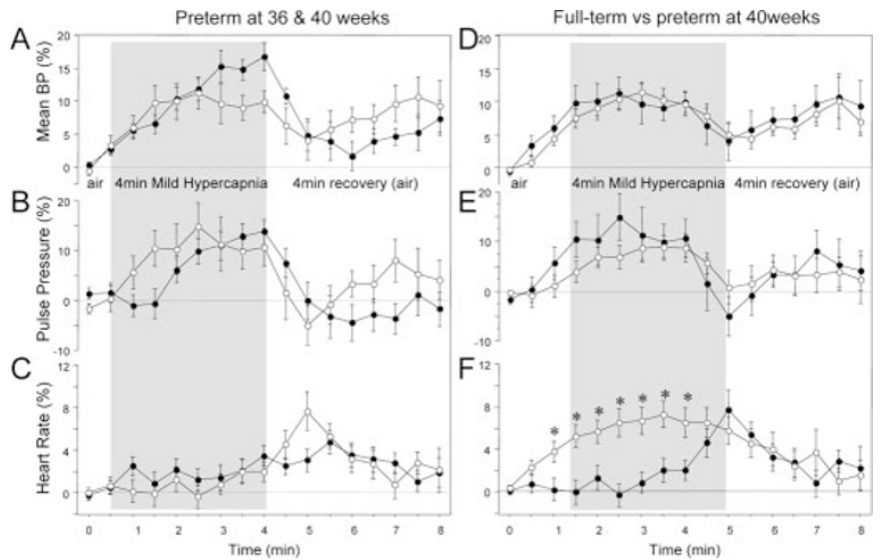

Figure 1. Cardiovascular responses of to $\mathrm{CO}_{2}$ during sleep. Preterm infants at 36 and $40 \mathrm{wk}$ are compared at left [A-C;36 wk (O), $40 \mathrm{wk}(\bigcirc) ; n=12]$ and preterm and term infants at the same age at right $[D-F$; preterm at $40 \mathrm{wk}$ (๑); full term (O), $n=12]$. The increase (and subsequent decrease) in BP was exaggerated at $36 \mathrm{wk}(A ; p=0.05)$, but had normalized by term $(D ; p=0.5)$. Pulse pressure of preterm infants increased more rapidly during $\mathrm{CO}_{2}$ exposure $(B, p=0.4 ; E, p=0.02)$. Only term infants had increased BP and HR when exposed to $\mathrm{CO}_{2}(C, p=0.09 ; F, p<0.001)$. Mean $\pm \mathrm{SEM} ; p$ values (two-way ANOVA) refer to group comparisons; $* p<0.05$.

The increase (and subsequent dramatic decrease) in pulse pressures was due principally to changes in systolic pressure (Fig. 3). $\mathrm{CO}_{2}$ exposure always caused mild bradycardia in BPD (Fig. 2D). Baseline $\mathrm{TcCO}_{2}$ levels fell slightly with age in severe BPD (Table 2), but circulatory responses of both BPD groups to $\mathrm{CO}_{2}$ did not change between 36 and $40 \mathrm{wk}$. There was no correlation between gestational/postnatal age and the pressor response of infants with BPD.

HVRs. Because breathing has mechanical and reflex effects on BP and HR, we looked for evidence of an association between the cardiovascular and ventilatory responses to $\mathrm{CO}_{2}$, i.e. did babies with the most vigorous ventilatory responses have the most (or least) vigorous BP or HR responses? As expected, $\mathrm{CO}_{2}$ consistently augmented breathing (Fig. $4 A, B$ ). The net increases in ventilation and breathing strategies were comparable, irrespective of gestation, age, or BPD grade (Fig. $4 C, D)$ and hence could not explain the dramatically reduced pressor response in severe BPD (Figs. $3 D$ and $4 D$ ). There was a strong correlation between HR and systolic $(p=0.006)$ but not diastolic BP $(p=0.06)$ responses, indicating that only systolic BP increased in parallel with HR. There was no association between the ventilatory and HR or BP responses to $\mathrm{CO}_{2}$ ( $p=0.77$ and 0.66 , respectively).

Cardiovascular control at term equivalent age. The principal findings at term are summarized in Figure 5. Infants born at this age responded to $\mathrm{CO}_{2}$ by increasing both $\mathrm{BP}$ and $\mathrm{HR}$, but those born preterm responded with either (i) a normal pressor but weak HR response (mild-moderate or no BPD) or (ii) an abnormally low pressor response confounded by mild cardiac depression (severe BPD).

\section{DISCUSSION}

Our data reveal that preterm birth is associated with persistently altered HR and in some circumstances abnormal pressor responses to mild stress (Fig. 5). These findings are remark-

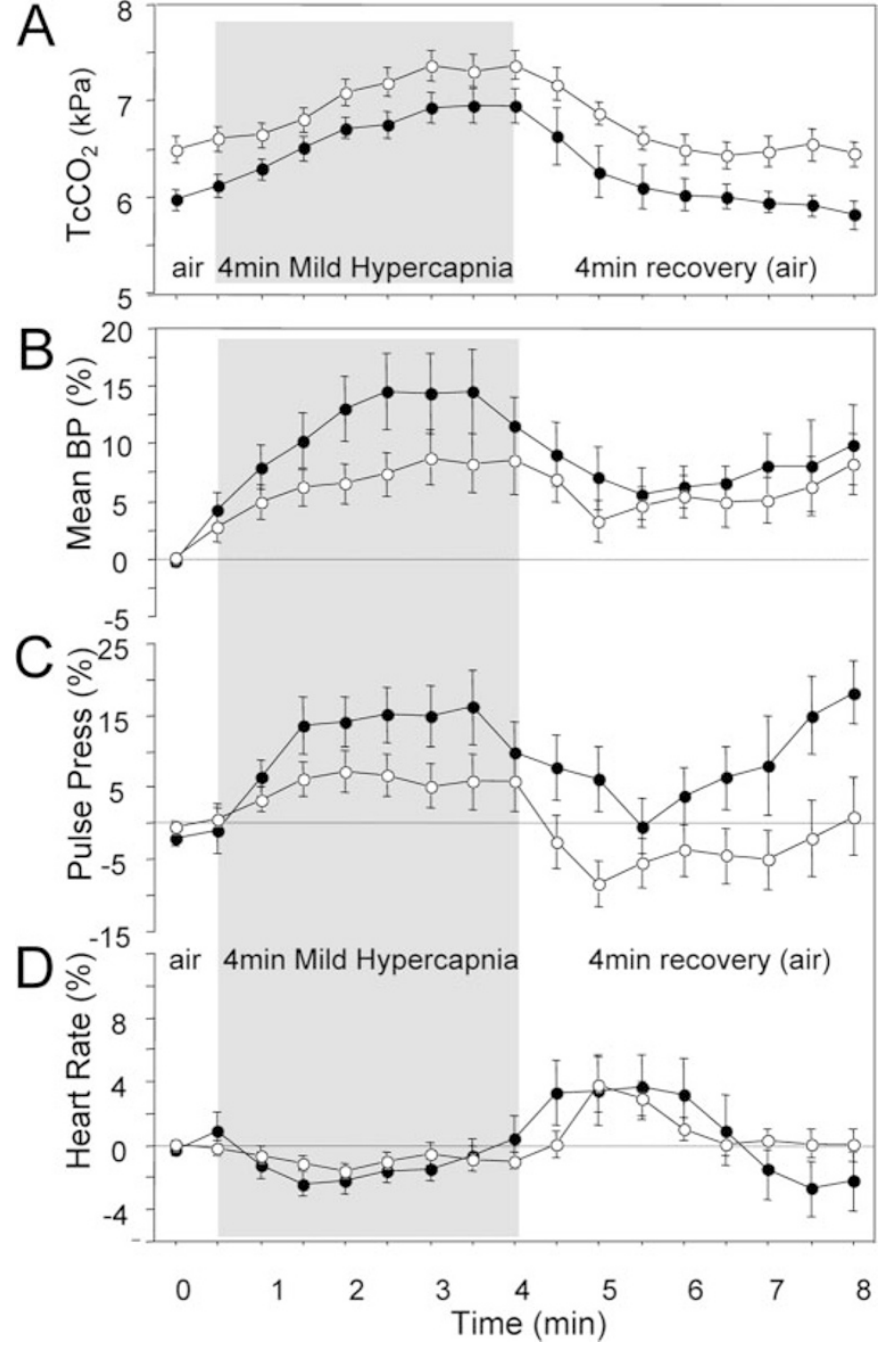

Figure 2. Cardiovascular responses to $\mathrm{CO}_{2}$ in $\mathrm{BPD} . \mathrm{TcCO}_{2}$ levels were elevated in severe BPD [A; mild-moderate $\operatorname{BPD}(\bullet), n=5$; severe BPD $(\bigcirc)$, $n=5 ; p<0.001$ for group $\times$ time ANOVA interaction]. Mean BP and pulse pressure were exaggerated in mild-moderate $\mathrm{BPD}$, and attenuated in severe BPD ( $B, C ; p=0.04$ and 0.01 for group comparisons, respectively). HR decreased during $\mathrm{CO}_{2}$ exposure, then increased transiently $(D ; p=0.2$ for group comparisons). Values are mean $\pm \mathrm{SEM}$.

able in view of the relatively small number of infants studied and the fact that we used indirect (although validated) techniques to measure arterial $\mathrm{CO}_{2}$ and pressures $(13,16,17)$. Clearly, short-term circulatory control is altered by being born too soon and may be further compromised by perinatal complications.

In adults, $\mathrm{CO}_{2}$ dilates the arteries and constricts the veins, lowering systemic resistance and elevating venous return, arterial and pulse pressures, and cardiac output. These actions, which redirect blood away from the periphery toward the brain and heart, are due to a chemoreceptor-mediated increase in sympathetic drive to the heart, blood vessels, and adrenals (18). Although $\mathrm{CO}_{2}$ itself slows HR (a vagal reflex), HR normally increases because cardiovagal inhibition is reversed by the accompanying hyperpnea $(19,20)$. Term infants respond to hypercapnia much like this, with a 7-10 Torr increase in $\mathrm{PCO}_{2}$ increasing HR and BP by $10 \%$, as occurs in adults. These changes develop more rapidly in infants, but the 


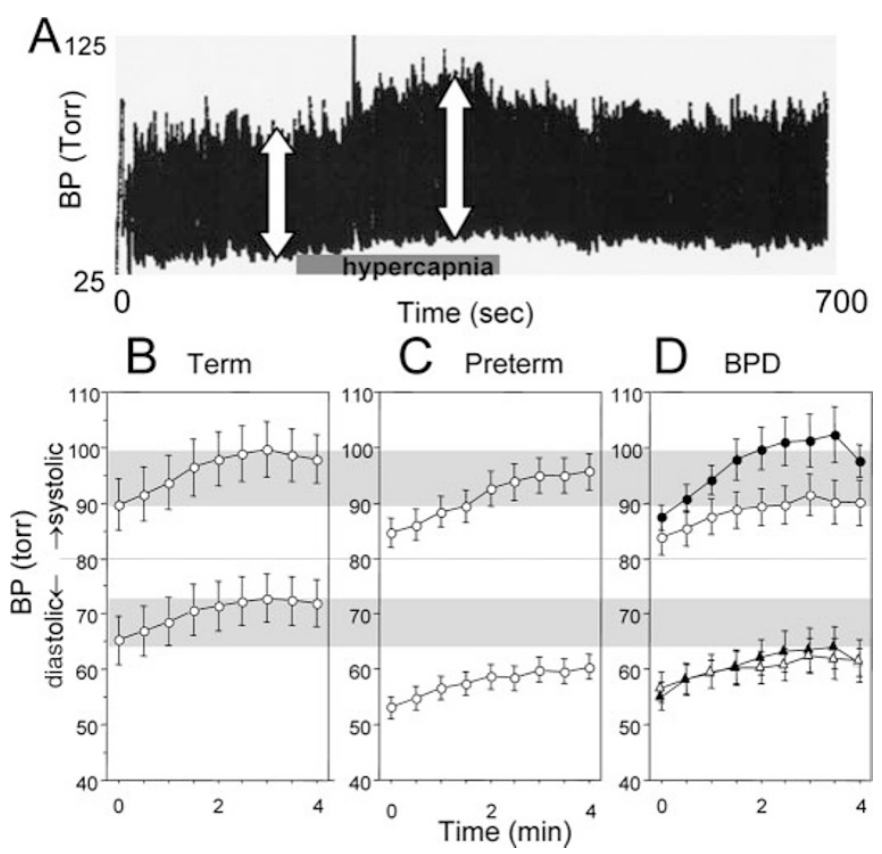

Figure 3. Absolute BP during hypercapnia. Systolic pressure changed more than diastolic pressure, shown by a compressed BP recording from one test ( $A$; pulse pressure is indicated by the arrows). Absolute systolic and diastolic pressures (upper/lower traces in each panel) illustrate differences between term $(B)$ and preterm babies without $(C)$ and those with BPD [D; mildmoderate (solid symbols) and severe (open symbols)]. Diastolic pressure was lower in preterm infants, and the systolic response was attenuated in severe BPD. Horizontal shading indicates the range for term babies.
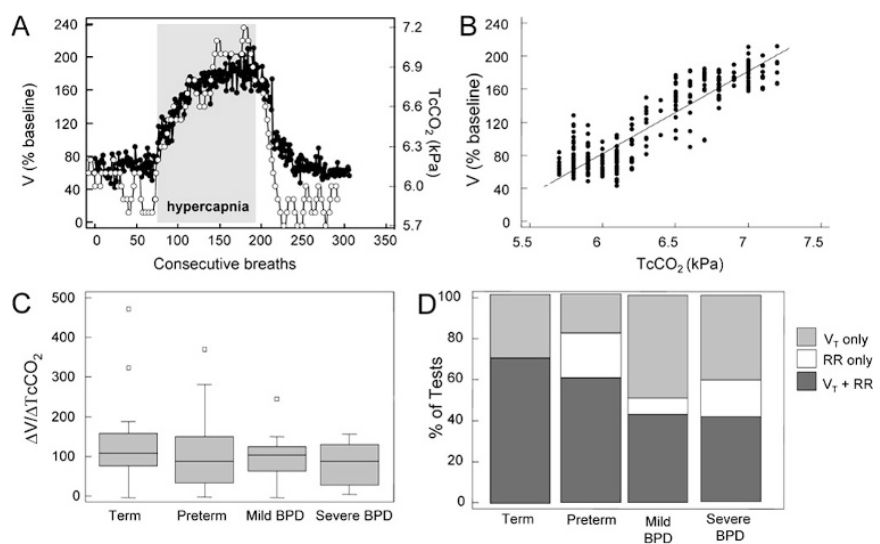

Figure 4. Ventilatory responses to $\mathrm{CO}_{2}$. The increase in ventilation (V) during a representative $\mathrm{CO}_{2}$ test is shown $\left[A\right.$; ventilation $\left.(\bullet) ; \mathrm{TcCO}_{2}(\mathrm{O})\right]$. The slope of $\mathrm{RR}, \mathrm{V}_{\mathrm{T}}$, and $\mathrm{V}\left(=\mathrm{RR} \times \mathrm{V}_{\mathrm{T}}\right)$ vs $\mathrm{TcCO}_{2}$ measured the strength of each response ( $B$ for data in $A ; r=0.89$ ). All groups had an equivalent increase in $\mathrm{V}$ during $\mathrm{CO}_{2}$ exposure [box-and-whiskers plots $(C), p=0.16$; medians are the lines inside the boxes]. Breathing strategy, the proportion of tests in which rate or depth of breathing (or both) increased during $\mathrm{CO}_{2}$ exposure, is compared $(D)$.

body stores which buffer changes in $\mathrm{CO}_{2}$ are correspondingly much smaller in infancy. At both ages, the pressor response outlasts the stimulus, most likely due to residual adrenergic stimulation by catecholamines released into the blood from the adrenal (21). The similarities between adults and infants suggest that (i) this cardiovascular chemoreflex arc is normally well developed at or soon after birth and (ii) elements of it may be fine-tuned as the heart and nervous systems mature, but the response itself changes little with age.

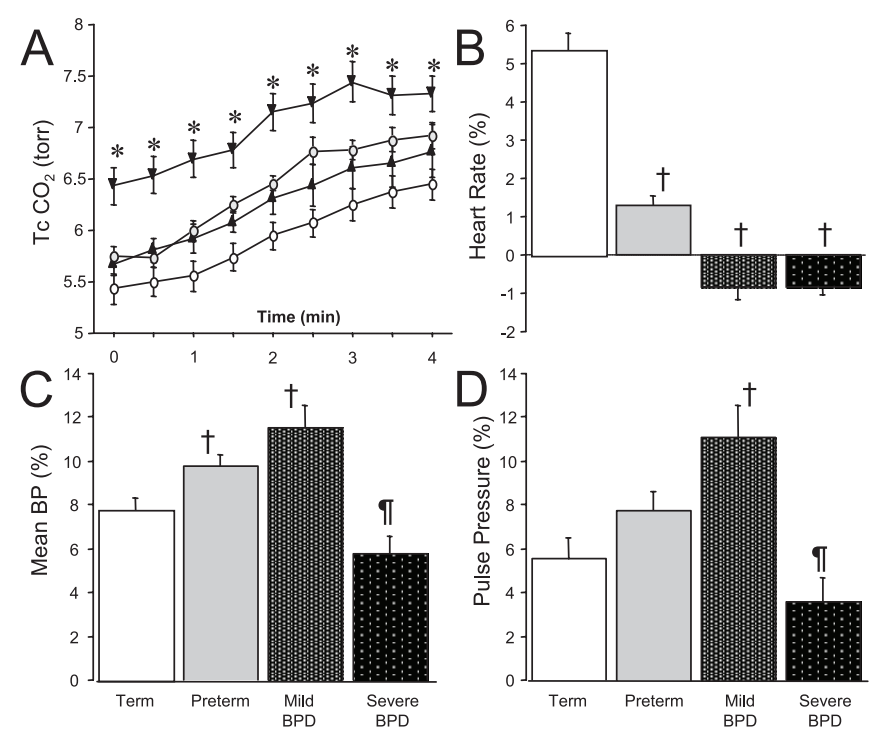

Figure 5. Principal findings at term age. $\mathrm{CO}_{2}$ profiles $(A)$ and mean $\mathrm{HR}$ and $\mathrm{BP}$ changes ( $B-D$; average over 4-min $\mathrm{CO}_{2}$ exposure) are shown. $\mathrm{CO}_{2}$ levels were higher in severe BPD, but the rate of change was comparable between groups $(A)$. Preterm HR increased only slightly in $\mathrm{CO}_{2}$ and decreased in BPD $(B)$. $\mathrm{BP}$ and pulse pressures increased more in preterms with mild-moderate or no BPD, but were attenuated in severe BPD $(C, D)$. Significant differences ( $p<0.05$ by ANOVA and multiple range tests) are indicated; $*$ different from all other groups; †different from term infants; Ifdifferent from mild-moderate BPD.

Although term infants exposed to $\mathrm{CO}_{2}$ increase both $\mathrm{BP}$ and HR (22), infants born preterm increase BP with little or no change in HR (Fig. 1). In fact, the preterm heart already beats $10 \%$ or so faster at rest, partly to compensate for lower systemic vascular resistance: because blood flows out of lowresistance (preterm) arteries more rapidly, this maintains diastolic filling and pressure (both lower in preterms; Fig. 3) (23). Under such circumstances, peripheral vasoconstriction (which boosts venous filling pressure and end-diastolic ventricular volume) may be the principal means of increasing BP during the initial minutes of $\mathrm{CO}_{2}$ exposure. The accompanying hyperpnea may also help because it lowers pleural pressure, which draws blood into the right side of the heart $(24,25)$. An exceptionally strong preterm vasoconstrictor reflex may compensate for the delayed cardioacceleratory response of the preterm infant to $\mathrm{CO}_{2}$. The latter suggests that preterm cardiac adrenergic receptors are stimulated mainly by circulating (adrenal) catecholamines rather than directly by sympathetic nerve terminals within the heart $(22,26)$. The younger the gestation, the steeper was the acute increase and subsequent decrease in, particularly, pulse pressure (Fig. 1). Acute changes in BP are buffered by the baroreflex, which adjusts HR and sympathetic tone to keep pressure changes within a narrow range. This reflex is active but functionally immature at $36 \mathrm{wk}$ and still relatively weak at $40 \mathrm{wk}$ (27). If the threshold for baroreflex activation is slow to reset to the usual postnatal range, dynamic variations in pressure may be wider than expected and remain so for much longer than is normal after birth, as we observed (28).

$\boldsymbol{B P D}$. BPD is a pathologic response of the immature lung to medical treatments used to support breathing and combat 
hypoxia. It occurs in approximately $30 \%$ of infants born extremely preterm, many of whom may remain symptomatic for months or years (12). Neonatal cardiovascular dynamics has not been studied systematically, although known complications of the severest forms of BPD include pulmonary hypertension, cardiac hypertrophy, and systemic hypertension $(8,9,29)$. Variations in practice, guidelines, and endpoints make it difficult to standardize grading of the severity of BPD. The criteria we used, $\mathrm{O}_{2}$ dependency at $36 \mathrm{wk}$ (12), is useful for several reasons: (i) it is used clinically to define BPD; (ii) $\mathrm{O}_{2}$ support $\geq 30 \%$ (severe) or $<30 \%$ (mild-moderate BPD) correlates reasonably well with the underlying hypoxia (measured by the decrease in saturation during $\mathrm{O}_{2}$ withdrawal), and (iii) prolonged $\mathrm{O}_{2}$ dependency correlates with long-term (respiratory) dysfunction (30).

We identified several reflex anomalies associated with BPD, including mild, hypercapnia-induced cardiac depression (bradycardia). This immature, fetal-like vagal response to $\mathrm{CO}_{2}$ is normally blocked/reversed after birth because lung inflation is cardioexcitatory. In BPD, however (irrespective of its severity), HR decreased despite a seemingly brisk ventilatory response to $\mathrm{CO}_{2}$ (Fig. 4). Why? One problem faced in this disease is that the lungs are stiff and difficult to inflate and keep inflated, so breathing tends to be rapid and shallow (31). If lung expansion is restricted and cardioexcitatory lung inflation afferents are only weakly activated in BPD, it may be difficult to counteract rapid, $\mathrm{CO}_{2}$-induced cardiac depression $(32,33)$. The slow, secondary increase in HR which occurred in healthy preterms exposed to $\mathrm{CO}_{2}$ was also largely absent in BPD; this may indicate impaired adrenal catecholamine release or altered cardiac adrenergic receptor activity caused by chronic sympathetic overactivation, both of which are complications of BPD (34-36). A strong cardiodepressant reflex of the sort we describe is a poor prognostic sign: it could trigger or deepen asphyxial coma or prevent cardiovascular autoresuscitation and may be a factor contributing to the high SIDS rate in $\operatorname{BPD}(6,10,37)$.

Unlike HR, disturbances in BP control varied with severity of lung disease. In mild-moderate $\mathrm{BPD}$, the pressor response to $\mathrm{CO}_{2}$ was exaggerated. Whether this is a side effect of lung disease per se is not clear because infants with BPD tend to be younger and smaller at birth than healthy preterms. BP may increase more when these infants are exposed to $\mathrm{CO}_{2}$ due to a combination of factors related to immaturity: strong sympathetic vasoconstrictor tone, a persistent cardioinhibitory reflex (a decrease in HR allows the heart more time to fill with blood, increasing cardiac output), and poor buffering of sudden increases in output and pressure due to a weak baroreflex. At the other end of the BPD spectrum, however, we observed a diminished pressor response and dramatic recovery fall off in pulse pressure. This suggests that the challenge in severe BPD may be to maintain pressure and perfusion and prevent it from decreasing (rather than increasing) too much, too quickly. A weak pressor response to stress may be a symptom of immaturity confounded by pathophysiological adaptations to chronic disease. Why short-term BP control is compromised in this way and why babies with severe BPD seem so close to failure is difficult to say. Chemoreceptor-mediated responses to hypercapnia may be diminished in severe BPD due either to chronic $\mathrm{CO}_{2}$ retention, or weakening of the sympathoadrenal system. $(18,35,38)$. Furthermore, because the head and upper body of these babies is often disproportionately large $(39,40)$, cerebral vasodilation during $\mathrm{CO}_{2}$ exposure could profoundly reduce systemic vascular resistance. Combined with an already high HR (which limits the heart's capacity to increase the volume and force of ventricular ejection) and a fast shallow breathing pattern (which does not facilitate venous return), stroke volume and pulse pressure may actually decrease (Fig. 2C). The decrease may be especially difficult to arrest or counteract because the baroreflex is still immature. These infants could consequently be vulnerable to episodes of spontaneous hypotension and hypoperfusion, a potentially serious situation given their rapid metabolism and precarious energy balance $(35,41)$.

Longer term consequences. The persistent differences that we observed between groups at term age indicate that circulatory control must develop more slowly or diverge from normal when babies are born too early. Ultimately, these changes can be traced to the sudden growth arrest occurring immediately after premature birth (40). Infants born preterm may eventually catch up to their counterparts born at term, although to what extent presumably depends on whether key events occur at the proper time and in the correct sequence, e.g. changes in baroreflex control (which normally strengthens), cardiovagal inhibition (which weakens), metabolism (which slowly decreases), vascular resistance (which increases), and within the heart itself $(27,42,43)$. Because the $\mathrm{HR}$ of the preterm infant is often elevated at $6 \mathrm{mo}$, central and peripheral mechanisms involved in cardiac (and perhaps circulatory) control may be quite slow to reset or normalize (if at all) (44). Presumably, and this requires long-term follow-up, the more severe and persistent the dysfunction (e.g. severe $\mathrm{BPD})$, the slower will be the path to recovery and the more likely it is that there will be enduring, perhaps serious, side effects. Dysfunction of the sort we describe may be further worsened by hypoxia (which amplifies the effects of hypercapnia, and is a complication of BPD) or nicotine exposure due to maternal tobacco use (45-47).

\section{CONCLUSION}

Short-term control of HR and BP is altered by preterm birth and superimposed chronic lung disease. Some of the reflex changes we describe could predispose to episodes of sudden hypotension and may be early signs of emerging long-term dysfunction.

Acknowledgments. The authors are indebted to Lena Legnevall, Viveca Karlsson, Eva Lundberg, Dr. Gerard Langewouters (Finapres Medical Systems), and Cees Ljizenga and Boris van Son (Rembrandt Automation) for expert assistance and advice.

\section{REFERENCES}

1. Hack M 2006 Young adult outcomes of very-low-birth-weight children. Semin Fetal Neonatal Med 11:127-137 
2. Bonamy A, Bendito A, Martin H, Andolf E, Sedin G, Norman M 2005 Preterm birth contributes to increased vascular resistance and higher blood pressure in adolescent girls. Pediatr Res 58:845-849

3. Johansson S, Iliadou A, Bergvall N, Tuvemo T, Norman M, Cnattingius S 2005 Risk of high BP among young men increases with the degree of immaturity at birth. Circulation 112:3430-3436

4. Kistner A, Jacobson L, Jacobson SH, Svensson E, Hellstrom A 2002 Low gestational age associated with abnormal retinal vascularization and increased BP in adult women. Pediatr Res 51:675-680

5. Harper RM, Kinney HC, Fleming PJ, Thach BT 2000 Sleep influences on homeostatic functions: implications for sudden infant death syndrome. Respir Physiol 119:123-132

6. Sridhar R, Thach BT, Kelly DH, Henslee JA 2003 Characterization of successful and failed autoresuscitation in human infants including those dying of SIDS. Pediatr Pulmonol 36:113-122

7. Robinson SM, Barker DJ 2002 Heart disease: a disorder of growth. Proc Nutr Soc 61:537-542

8. Abman SH 2002 Monitoring cardiovascular function in infants with chronic lung disease of prematurity. Arch Dis Child Fetal Neonatal Ed 87:F15-F18

9. Korhonen P 2005 Cardiovascular findings in very low birthweight schoolchildren with and without bronchopulmonary dysplasia. Early Hum Dev 81:497-505

10. Werthammer J, Brown ER, Neff RK, Taeusch HW 1982 Sudden infant death syndrome in infants with bronchopulmonary dysplasia. Pediatrics 69:301-304

11. Cohen G, Katz-Salamon M 2005 Development of chemoreceptor responses in infants. Respir Physiol Neurobiol 149:233e-242e

12. Jobe AH, Bancalari E 2001 NICHD/NHLBI/ORD Workshop Summary. Bronchopulmonary Dysplasia. Am J Respir Crit Care Med 163:1723-1729

13. Andriessen P, Schoffelen RL, Berendsen RC, De Beer NA, Oei SG, Wijn PF, Blanco CE 2004 Noninvasive assessment of blood pressure variability in preterm infants. Pediatr Res 55:220-223

14. Prechtl HF 1974 The behavioral states of the newborn infant (a review). Brain Res $76: 185-212$

15. Katz-Salamon M, Milerad J 1998 The divergent ventilatory and HR response to moderate hypercapnia in infants with apnoea of infancy. Arch Dis Child 79:231-236

16. Wimberley PD, Burnett RW, Covington AK, Maas AH, Mueller-Plathe O, SiggaardAndersen O, Weisberg HF, Zijlstra WG 1990 Guidelines for transcutaneous pO2 and pCO2 measurement. JIFCC 2:128-135

17. Wenzel U, Wauer RR, Schmalisch G 1999 Comparison of different methods for dead space measurements in ventilated newborns using CO2-volume plot. Intensive Care Med 25:705-713

18. Kregenow DA, Swenson ER 2002 The lung and carbon dioxide: implications for permissive and therapeutic hypercapnia. Eur Respir J 20:6-11

19. Oikawa S, Hirakawa H, Kusakabe T, Nakashima Y, Hayashida Y 2005 Autonomic cardiovascular responses to hypercapnia in conscious rats: the roles of the chemoand baroreceptors. Auton Neurosci 117:105-114

20. Daly MB, Kirkman E 1989 Differential modulation by pulmonary stretch afferents of some reflex cardioinhibitory responses in the cat. J Physiol 417:323-341

21. Cooper VL, Pearson SB, Bowker CM, Elliott MW, Hainsworth R 2005 Interaction of chemoreceptor and baroreceptor reflexes by hypoxia and hypercapnia- a mechanism for promoting hypertension in obstructive sleep apnoea. J Physiol 568:677687

22. Robinson RB 1996 Autonomic receptor-effector coupling during post-natal development. Cardiovasc Res 31:E68-E76

23. Jones JE, Jose PA 2004 Neonatal blood pressure regulation. Semin Perinatol 28:141-148

24. Lagercrantz H, Edwards D, Henderson-Smart D, Hertzberg T, Jeffery H 1990 Autonomic reflexes in preterm infants. Acta Paediatr Scand 79:721-728

25. Nichols SD, Boyne MS, Thame M, Osmond C, Wilks RJ, Bennett FI, McFarlaneAnderson N, Young RE, Forrester TE 2005 Cold-induced elevation of forearm vascular resistance is inversely related to birth weight. J Hum Hypertens 19:309-314
26. Lagercrantz H, Marcus C 1992 Sympathoadrenal mechanisms during development. In: Polin RA, Fox WW (eds) Fetal and neonatal physiology. WB Saunders, Philadelphia, pp 161-169

27. Gournay V, Drouin E, Roze JC 2002 Development of baroreflex control of heart rate in preterm and full term infants. Arch Dis Child Fetal Neonatal Ed 86:F151-F154

28. Dawes GS, Johnston BM, Walker DW 1980 Relationship of arterial pressure and HR in fetal, new-born and adult sheep. J Physiol 309:405-417

29. Stenmark KR, Abman SH 2005 Lung vascular development: implications for the pathogenesis of bronchopulmonary dysplasia. Annu Rev Physiol 67:623-661

30. Walsh MC, Yao Q, Gettner P, Hale E, Collins M, Hensman A, Everette R, Peters N, Miller N, Muran G, Auten K, Newman N, Rowan G, Grisby C, Arnell K, Miller L, Ball B, McDavid G 2004 Impact of a physiologic definition on bronchopulmonary dysplasia rates. Pediatrics 114:1305-1311

31. Hey EN, Lloyd BB, Cunningham DJ, Jukes MG, Bolton DP 1966 Effects of various respiratory stimuli on the depth and frequency of breathing in man. Respir Physiol 1:193-205

32. Boushey HA, Richardson PS 1973 The reflex effects of intralaryngeal carbon dioxide on the pattern of breathing. J Physiol 228:181-191

33. Walker DW 1984 Peripheral and central chemoreceptors in the fetus and newborn. Annu Rev Physiol 46:687-703

34. Banks BA, Stouffer N, Cnaan A, Ning Y, Merrill JD, Ballerd RA, Ballard PL 2001 Association of plasma cortisol and chronic lung disease in preterm infants. Pediatrics 107:494-498

35. Bauer J, Maier K, Muehlbauer B, Poeschl J, Linderkamp O 2003 Energy expenditure and plasma catecholamines in preterm infants with mild chronic lung disease. Early Hum Dev 72:147-157

36. Noori S, Seri I 2005 Pathophysiology of newborn hypotension outside the transitional period. Early Hum Dev 81:399-404

37. Meny RG, Carroll JL, Carbone MT, Kelly DH 1994 Cardiorespiratory recordings from infants dying suddenly and unexpectedly at home. Pediatrics 93:44-49

38. Bavis RW, Johnson RA, Ording KM, Otis JP, Mitchell GS 2006 Respiratory plasticity after perinatal hypercapnia in rats. Respir Physiol Neurobiol 153:78-91

39. Abdulrazzaq YM, Brooke OG 1988 Is the raised metabolic rate of the small for gestational age infant due to his relatively large brain size. Early Hum Dev $16: 253-261$

40. Ehrenkranz RA, Younes N, Lemons JA, Fanaroff AA, Donovan EF, Wright LL, Katsikiotis V, Tyson JE, Oh W, Shankaran S, Bauer CR, Korones SB, Stoll BJ, Stevenson DK, Papile L 1999 Longitudinal growth of hospitalized very low birth weight infants. Pediatrics 104:280-289

41. Olhager E, Forsum E 2003 Total energy expenditure, body composition and weight gain in moderately preterm and full-term infants at term postconceptional age. Acta Paediatr 92:1327-1334

42. Ramet J, Praud JP, D'Allest AM, Carofilis A, Dehan M, Guilleminault C, Gaultie C 1988 Effect of maturation on HR response to ocular compression test during rapid eye movement sleep in human infants. Pediatr Res 24:477-480

43. Hew KW, Keller KA 2003 Postnatal anatomical and functional development of the heart: a species comparison. Birth Defects Res B Dev Reprod Toxicol 68:309-320

44. Henslee JA, Schechtman VL, Lee MY, Harper RM 1997 Developmental patterns of heart rate and variability in prematurely-born infants with apnea of prematurity. Early Hum Dev 47:35-50

45. Huang ZG, Griffioen KJ, Wang X, Dergacheva O, Kamendi H, Gorini C, Bouairi E, Mendelowitz D 2006 Differential control of central cardiorespiratory interactions by hypercapnia and the effect of prenatal nicotine. J Neurosci 26:21-29

46. Cohen G, Roux JC, Grailhe R, Malcolm G, Changeux JP, Lagercrantz H 2005 Perinatal exposure to nicotine causes deficits associated with a loss of nicotinic receptor function. Proc Natl Acad Sci U S A 102:3817-3821

47. Young M, Cottom D 1966 Arterial and venous blood pressure responses during a reduction in blood volume and hypoxia and hypercapnia in infants during the first two days of life. Pediatrics 37:733-742 